- The aim of the paper is to inform about the clinical indications, technique, success and safety of the Dahl concept, and to encourage the use of this valuable clinical technique.

The Dahl concept can be successfully applied to a variety of clinical situations other than the management of tooth surface loss.

- Direct composite resin is an ideal material to use as an intermediate Dahl appliance as it is inexpensive, bondable, robust and can be modified with ease.

\title{
The Dahl Concept: past, present and future
}

\author{
N. J. Poyser, ${ }^{1}$ R. W. J. Porter, ${ }^{2}$ P. F. A. Briggs, ${ }^{3}$ H. S. Chana ${ }^{4}$ and M. G. D. Kelleher ${ }^{5}$
}

The Dahl appliance was described nearly 30 years ago. This removable metal bite platform was used to create inter-occlusal space, in a localised part of the mouth, to facilitate the placement of restorations on worn anterior teeth. The Dahl concept is traditionally associated with the management of worn teeth. However, the same principles can be successfully and safely applied to a variety of clinical situations. This has simplified the management of historically complex problems. The advantages are the preservation of tooth tissue and the long-term benefits that brings. This paper reviews the literature related to the Dahl concept and how the concept has developed. There is a discussion regarding possible future applications and research.

\section{INTRODUCTION}

Tooth Surface Loss (TSL) is a normal physiological process that occurs throughout life. ${ }^{1}$ However, if the rate of wear challenges the viability of teeth, or is a source of concern to the patient, then the TSL may be considered pathological. ${ }^{2}$ The effective management of patients with TSL is an ongoing and increasing challenge for the dental profession. The condition can affect both ends of the age spectrum and thus affect a large proportion of the population. The Adult Dental Health Survey of 1998 reported that two thirds of adults had some wear into dentine on their anterior teeth, 11\% had moderate wear with extensive involvement of dentine and 1\% had severe wear. ${ }^{3}$ The Child Dental Health Survey of 1993 identified that 32\% of 14year-olds had evidence of erosion affecting the palatal surfaces of their permanent incisors. ${ }^{4}$ The prevalence of tooth wear is likely to escalate as life expectancy continues to increase. As people expect to retain their teeth throughout life this has important implications on the type of preventative and restorative care that the profession will need

\footnotetext{
1*Specialist Registrar in Restorative Dentistry, GKT Dental Institute of King's College London, Mayday and St George's Hospitals, London; 2,3GKT Dental Institute of King's College London and St George's Hospital, London; 4St George's and Kingston Hospitals, London; ${ }^{5}$ GKT Dental Institute of King's College London, Royal Surrey, Kent and Canterbury Hospitals. ${ }^{*}$ Correspondence to: Neil Poyser Email:neil.poyser@stgeorges.nhs.uk
}

\section{Refereed Paper}

Received 11.12.03; Accepted 02.06.04

doi: 10.1038/sj.bdj.4812371

๑ British Dental Journal 2005; 198: 669-676 to provide in the future. This also has an implication for training and funding for dental services. The management of TSL and the eventual failure of restorations placed to manage this problem are likely to be a significant issue in future years. Appropriate audit and research into the success and cost effectiveness of the management of TSL is important, in order that the clinical techniques and concepts used are supported by robust evidence. This information will also help the debate, within the profession, of whether, when and how restorative intervention is indicated for worn teeth.

\section{Managing loss of inter-occlusal space}

In the majority of patients, TSL is accompanied by dento-alveolar compensation. ${ }^{1}$ These physiological compensatory processes ensure that, for the majority of patients, occlusal contacts are maintained in order to maintain the efficacy of the masticatory apparatus. ${ }^{1}$ The apparent lack of interocclusal space presents a dilemma for the restorative dentist, especially where the TSL is localised. One approach is to conform to the existing intercuspal position (ICP) and create the necessary interocclusal space by further occlusal reduction of the worn teeth. Employing this conventional prosthodontic approach can however, have severe adverse sequelae. Occlusal reduction of worn teeth may lead to a lack of axial height and thus insufficient retention and resistance for conventional extra-coronal restorations. Surgical crown lengthening procedures may appear to be helpful but unfortunately introduce other disadvantages. Tooth preparation and the associated loss of coronal tissue can risk further insult to the pulp and limit the options for future restoration replacement.

An alternative approach is to create the necessary space by reorganising the occlusion by means of an arbitrary increase of the vertical dimension of occlusion. A different variation involves reconstruction of the occlusion to a retruded contact position (RCP). However, this can lead to restorations being placed on multiple unaffected teeth that can increase the complications of long-term maintenance.

Orthodontic appliances can be used to create sufficient inter-occlusal space by a combination of relative vertical and horizontal bodily movements and a change in the axial inclination of the teeth. ${ }^{5}$ These comprehensive and specialised techniques may be more appropriate when other features of the occlusion require treatment (such as anterior crowding) as a localised bite-raising Dahl appliance can create the necessary space.

Conventional versus adhesive restorations The dental profession is gradually accepting that destructive restorative procedures, involved in the placement of full coverage restorations, have a significant biological downside. Saunders and Saunders ${ }^{6}$ reported that in a Scottish subpopulation 19\% of crowned teeth (with presumably pre-operative vital status) had radiographic signs of peri-radicular disease. Felton and Madison demonstrated similar findings. ${ }^{7}$ The 
profession are also increasingly accepting that restorations will fail and are communicating this to patients at the outset. It is likely that numerous replacements will be required in a young/middle-aged patient's lifetime. It is our opinion that a conservative technique using adhesive principles will ensure that sufficient tooth structure with favourable pulpal health will remain for subsequent restorations and therefore more options should be available on failure. The modern emphasis should be of 'tooth damage limitation' as patients embark on the 'restorative failure cycle'.

The development and continuous improvement of adhesive dentistry materials has fortunately revolutionised the management of patients with TSL. The use of adhesive materials in the management of TSL has been well reported in the dental literature. Materials such as direct composite $^{8} \quad$ indirect composite, ${ }^{9}$ ceromer/polyglass material, ${ }^{9,10}$ porcelain veneers, ${ }^{11,12}$ the double veneer technique, ${ }^{13}$ dentine bonded crowns, ${ }^{14}$ nonprecious metal alloys (Nickel-Chromium), precious metal alloy, ${ }^{13}$ gold alloys ${ }^{15,16}$ and canine risers ${ }^{17}$ have all been used to restore teeth and to limit further damage of tooth structure.

\section{The Dahl Concept}

The Dahl Concept refers to the relative axial tooth movement that is observed when a localised appliance or localised restorations are placed in supra-occlusion and the occlusion re-establishes full arch contacts over a period of time. Other phrases such as "minor axial tooth movement', ${ }^{8,19}$ 'fixed orthodontic intrusion appliances', 'localised inter-occlusal space creation', and 'relative axial tooth movement' 20 have been used to describe the same process. The concept of relative axial tooth movement was recognised, and published, prior to Dahl et al.'s work of $1975 .{ }^{21}$ The anterior bite platforms of removal orthodontic appliances were, and still are, used for overbite reduction. ${ }^{22}$ However, these were used in the growing child during the period of dento-alveolar development. In 1962, Andersen ${ }^{23}$ described the idea of experimental malocclusion by placing restorations in supraocclusion. A $0.5 \mathrm{~mm}$ metal bite-raising cap was placed on the occlusal surface of the right lower first permanent molar in five human adult subjects (aged between 1940 years). After the experimental period of 23-41 days the subjects were able to bring their teeth into occlusal contact with the cap in position. The increased distance between the reference points on the capped tooth and the opponent indicated actual separation of these teeth with the creation of an inter-occlusal space. How-

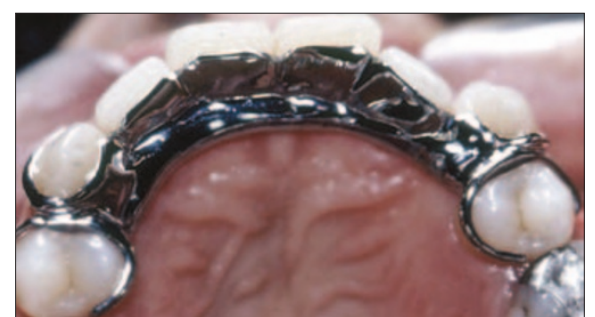

Fig. 1 A removable cobalt-chromium partial bite-raising appliance.

ever, the lack of fixed reference points meant that it was not possible to determine whether the movement was due to eruption of the separated teeth, intrusion of the teeth contacting the bite-raising cap, or a combination of both.

Dahl was the first author through a series of papers to report the successful use of the technique for the management of the worn dentition. In the initial paper in 1975, Dahl, Krogstad and Karlsen ${ }^{21}$ described the use of a "partial bite raising appliance' to create inter-occlusal space in an 18 year old with severe localised attrition. The removable appliance was cast in cobalt-chromium, placed on the palatal aspects of the upper anterior teeth, and worn 24 hours a day. After a period of eight months sufficient space was created to provide palatal gold pinlays for the worn upper anterior teeth. An example of a similar appliance is shown in Figure 1. Dahl and Krogstad's further publications $^{24-26}$ of an implant-cephalometric study, using fixed tantalum implants placed in the basal bone of the maxilla and mandible, concluded that the interocclusal space was created by axial movement of the teeth ${ }^{24}$ rather than a change in their inclination. ${ }^{25}$ There was some relapse in the vertical dimension of occlusion during the first six months but this remained static after this period. ${ }^{26}$ The inter-occlusal space was obtained by a combination of intrusion of the anterior teeth in contact with the cobalt-chromium appliance and eruption of the seperated posterior teeth.

Dahl deserves credit as he discovered a significant role for this technique in the management of the localised tooth surface loss. Unfortunately, Dahl did not have access to the adhesive materials and techniques of today and unfortunately his patients' teeth were restored with full coverage porcelain bonded crowns once sufficient inter-occlusal space had been created. However, the creation of inter-occlusal space significantly reduced the amount of tooth preparation required, especially on the already compromised palatal surface. It is from this benchmark that other workers have developed less invasive techniques to manage this traditionally difficult clinical problem. Depressingly, it appears that there has been limited accept- ance and application of this technique by the dental profession, despite favourable reports in the literature for over two decades.

Interestingly, the majority of the more recent literature in this area originates from the United Kingdom. There might be many reasons for the lack of international uptake of this technique. Dentists might feel more confident in performing conventional prosthodontic techniques and feel that this provides a more predictable and durable outcome compared with the Dahl concept. Practitioners may be cautious about adopting the Dahl concept as this technique may be in conflict with their traditional taught principles of occlusion. In addition, the remuneration system within which practitioners work may dissuade them from using such a technique.

The evidence relating to the Dahl concept is presented in Table 1 . The studies were identified by conducting an electronic search of the Cochrane Oral Health Group Trials Register, the Cochrane Central Register of Controlled Trials, and MEDLINE (1966 to present) via OVID. The following terms were used with MEDLINE: Tooth Attrition, Tooth Abrasion, Tooth Erosion, Orthodontic-Appliances, Tooth-Movement. The results of the searches were assessed and only relevant clinical studies were selected for this paper.

Two retrospective and three prospective clinical studies were identified. The quality of the level of evidence from these studies is medium to low (level IIb and III as determined by the Royal College of Surgeons National Clinical Guidelines criteria). ${ }^{27}$ Unfortunately the designs of the studies do not minimise the potential for examiner bias. There is the absence of control groups and blinded examiners, and many of the observations are made using subjective rather than objective assessments. We have to be aware of the limitations of the data and the strength of the conclusions that can be drawn from these five studies. The current focus is on evidence-based dentistry and the 'gold standard' of randomised controlled clinical trials. However, it must be remembered that there is a wealth of 'low quality evidence' relating to interventions that may provide great benefit for patients. Without the dissemination of this information the potential of these beneficial techniques would be unknown and the development of further techniques and research hindered. If 'low quality evidence' is to be published the limitations need to be recognised and recommendations given on how to optimise the design and credibility of future studies.

Dahl's ${ }^{24}$ original work relates to the creation of inter-occlusal space in the 


\begin{tabular}{|c|c|c|c|c|c|c|c|}
\hline Author & $\begin{array}{l}\text { Method of } \\
\text { space creation }\end{array}$ & $\begin{array}{l}\text { Area of } \\
\text { space creation }\end{array}$ & Aetiology & No of Patients & $\begin{array}{l}\text { Increase in OVD } \\
(\mathrm{mm})\end{array}$ & Success Rate & $\begin{array}{l}\text { Time for space } \\
\text { creation } \\
\text { range (months) }\end{array}$ \\
\hline Study Design & & & Area affected & M:F Ratio & & & mean (months) \\
\hline Period of Follow-Up & & & & $\begin{array}{l}\text { Age Range (years) } \\
\text { (mean) }\end{array}$ & & & \\
\hline Dahl and Krogstad $1982^{24}$ & $\begin{array}{l}\text { Removable Co-Cr } \\
\text { anterior bite platforn } \\
\text { (interim appliance) }\end{array}$ & Anterior & Attrition & 20 & $1.8-4.7$ & $\begin{array}{l}100 \%(20 / 20) \\
\text { adequate space } \\
70 \%(14 / 20)\end{array}$ & $6-14$ \\
\hline Prospective & & & $\begin{array}{l}\text { Anterior Maxilla/ } \\
\text { Mandible }\end{array}$ & $14: 6$ & & planned space & Not stated \\
\hline 14 months & & & & $18-50(34.7)$ & & & \\
\hline Gough and Setchell $1999^{20}$ & $\begin{array}{l}78 \% \text { cemented } \\
22 \% \text { removable } \\
\text { (interim appliance) }\end{array}$ & $\begin{array}{l}68 \% \text { anterior } \\
32 \% \text { posterior } \\
76 \% \text { maxilla } \\
24 \% \text { mandible }\end{array}$ & $\begin{array}{l}\text { TSL, over-eruption, } \\
\text { iatrogenic, failed } \\
\text { orthodontics }\end{array}$ & $\begin{array}{l}45 \\
\text { (50 appl.) }\end{array}$ & $\begin{array}{l}\text { Unknown } \\
\text { - not all pre } \\
\text { and post- } \\
\text { operative casts }\end{array}$ & $96 \%(48 / 50)$ & $0.93-24$ \\
\hline Retrospective & & & $\begin{array}{l}\text { Anterior/Posterior } \\
\text { Maxilla/Mandible }\end{array}$ & $21: 24$ & available & & 5.9 \\
\hline $\begin{array}{l}\text { Median } 4.43 \mathrm{yrs} \\
\text { (up to } 14.1 \mathrm{yrs} \text { ) }\end{array}$ & & & & $20-70(37)$ & & & \\
\hline Hemmings et al. $2000^{8}$ & $\begin{array}{l}\text { Direct Composite } \\
\text { Restorations }\end{array}$ & Anterior & 'Severe TSL' & 16 & $1-4$ & $94 \%(15 / 16)$ & $1-11$ \\
\hline Prospective & $\begin{array}{l}\text { (appliance and } \\
\text { definitive restoratic }\end{array}$ & & $\begin{array}{l}\text { Anterior Maxilla/ } \\
\text { Mandible }\end{array}$ & Not stated & & & 4.6 \\
\hline Mean 30 months & & & & $19-54(33.8)$ & & & \\
\hline Gow and Hemmings $2002^{10}$ & $\begin{array}{l}\text { Indirect Artglass }{ }^{\circledR} \\
\text { Restorations }\end{array}$ & Anterior & 'Advanced TSL' & 12 & $1-4$ & $83 \%(10 / 12)$ & $6-12$ \\
\hline Prospective & $\begin{array}{l}\text { (appliance and } \\
\text { definitive restoratic }\end{array}$ & & Anterior Maxilla & Not stated & & & 9 \\
\hline $\min$ of $2 y r s$ & & & & $17-61(36)$ & & & \\
\hline Redman et al. $2003^{9}$ & $\begin{array}{l}\text { Direct and Indirect } \\
\text { Composite and } \\
\text { Artglass }^{\circledR}\end{array}$ & Anterior & $\begin{array}{l}\text { Erosive, Attrition } \\
\text { and Combined TSL }\end{array}$ & 31 & Not stated & $\begin{array}{l}100 \%(31 / 31) \\
61 \% \text { complete } \\
39 \% \text { partial }\end{array}$ & $1.5-18.5$ \\
\hline Retrospective & $\begin{array}{l}\text { Restorations } \\
\text { (appliance and }\end{array}$ & & $\begin{array}{l}\text { Anterior Maxilla/ } \\
\text { Mandible }\end{array}$ & $(22: 9)$ & & & 7 \\
\hline $5 m-6 y r s$ & definitive restorati & & & $15-70($ not stated) & & & \\
\hline
\end{tabular}

anterior region due to worn maxillary anterior teeth. Gough and Setchell ${ }^{20}$ published a retrospective evaluation of the outcome and factors relating to the creation of localised inter-occlusal space following localised TSL, overeruption following the loss of an antagonist tooth or extracoronal restoration. Localised interocclusal space was created with the use of an interim appliance, which in the majority of cases, was a cemented cobalt-chromium appliance. Appliances were placed in the anterior or posterior aspects of the maxillary or mandibular dentition. Hemmings and co-workers have published a series of papers focusing on the performance of different types of composite restoration used for the management of anterior tooth surface loss. ${ }^{8-10}$ The larger retrospective evaluation by Redman et al. ${ }^{9}$ may include a significant number of the patients and restorations assessed in the previous papers. ${ }^{8,10}$

\section{Definition of a Dahl appliance}

The design and materials used to construct the appliance have changed dramatically since Dahl's original cobalt chromium appliance. Many materials can be used to construct such an appliance as long as the principles of the technique are adhered to. The aims of a Dahl appliance are given below.

A thickness of material should be placed on the incisal/occlusal aspect of those teeth where the creation of interocclusal space is necessary. There should be no mucosal-borne component.

The thickness of this material placed should directly relate to the amount of inter-occlusal space that is required. This will determine the increase in the vertical dimension of occlusion as measured at that particular site in the mouth.

Ideally an occlusal bite platform should be constructed to ensure that occlusal forces are directed along the long axis of the teeth.

Stable inter-occlusal contacts should be provided.

The appliance should not impede the movement of the discluded teeth.

The success of the Dahl Concept

The literature reports that the objectives of the Dahl concept are achieved in the majority of cases (94\%-100\%), , 80,24 and that this space creation occurs irrespective of age and sex. These objectives are to either create sufficient inter-occlusal space for the placement of restorations or the re-establishment of occlusal contacts following the placement of restorations that have intentionally been placed in supra-occlusion.

The main reason for the failure of space creation is poor patient compliance associated with removable appliances. $^{20,24}$ Indeed Dahl and Krogstad ${ }^{24}$ suggested that the conscientiousness with which the splint is worn is the most decisive factor for space creation. The studies by Hemmings et al., ${ }^{8}$ Gow and Hemmings, ${ }^{10}$ and Redman et al. ${ }^{9}$ all relate to fixed 'appliances' (definitive adhesive restorations), and 78\% of the appliance in Gough and Setchell's ${ }^{20}$ study were cemented. The use of fixed Dahl appliances has eliminated poor patient compliance as a reason for failure of space creation. The other reasons for failure of space creation are rare. Hemmings et al. ${ }^{8}$ reported the failure of space creation in a patient with a gross class III malocclusion and mandibular facial asymmetry that had a lack of stable occlusal contacts in ICP or RCP. Gough and Setchell ${ }^{20}$ reported 
failing to intrude two lower incisors in a 56-year-old male. The reason for this was unclear. Gow and Hemmings ${ }^{10}$ reported the failure of the occlusion to re-establish in two out of 12 patients (17\%). They attributed this to the continued wear of a lower soft night guard immediately following treatment in one patient. They considered the lack of eruptive potential as the cause in the other patient. Redman et $a l .{ }^{9}$ reported complete re-establishment of the occlusal contacts in $61 \%$ of cases and partial re-establishment in $39 \%$. These authors noted that a third of patients did not achieve posterior contacts in the premolar region. They suggested that this might be due to a limit to the premolar eruptive potential or that the premolars might have become impacted behind the canine. It might be possible that these patients were still undergoing occlusal re-establishment and were simply reviewed too soon. Unfortunately the authors did not specify in which cases this occurred or whether this was of practical significance to the patient. There was no mention of the increase in the vertical dimension of occlusion or how long the restorations had been placed and reviewed. Continued occlusal re-establishment might occur in these patients and, as Gough et al. ${ }^{20}$ have suggested, virtually all appliances will produce localised space if allowed enough time.

The fact, however, that Redman et al. ${ }^{9}$ have reported only partial occlusal reestablishment in a significant proportion of their cases questions why this was not reported in the other papers and how these papers assessed whether the Dahl appliance and occlusal re-establishment was successful. At present there is no definitive classification as to the success of the occlusal re-establishment and when precisely to assess the definitive outcome. Some clinicians would suggest that it is failure if full arch occlusal re-establishment is incomplete but there is no time period stated as to how long such a process is allowed to take. The high success rates reported in the other papers may be because they categorised 'no apparent tooth movement' as a failure ${ }^{20}$ and some tooth movement, either partial or complete occlusal re-establishment, as a success. Although complete occlusal re-establishment is desirable it is only one aspect by which to determine the success of the treatment.

In the rare event that occlusal re-establishment fails to occur or is incomplete then this may not necessarily be a significant problem. Some patients function perfectly well with the reduced number of occlusal contacts and no further interven-

\begin{tabular}{lll}
\multicolumn{2}{l}{ Table $\mathbf{2}$ The time taken for space creation } & to occur as reported in the five main studies \\
\hline Author & $\begin{array}{l}\text { Time for space creation } \\
\text { (Range in months) }\end{array}$ & $\begin{array}{l}\text { Time for space creation } \\
\text { (Mean in months) }\end{array}$ \\
\hline Dahl and Krogstad $1982^{24}$ & $6-14$ & Not stated \\
\hline Gough and Setchell $1999^{20}$ & $0.93-24$ & 5.9 \\
\hline Hemmings et al. $2000^{8}$ & $1-11$ & 4.6 \\
\hline Gow and Hemmings $2002^{10}$ & $6-12$ & 9 \\
\hline Redman et al. $2003^{9}$ & $1.5-18.5$ & 7
\end{tabular}

tion is required. If more occluding pairs are required then it is possible to provide the further restorations by adhesive or other techniques just as if the occlusion were being reorganised in the retruded jaw position at an increased vertical dimension of occlusion. The technique will still have been significantly more conservative than restoring the teeth with conventional prosthodontic techniques at the existing ICP.

\section{How much space can be created?}

An increase in the vertical dimension of occlusion in a dentate patient does not seem to have the associated problems as reported in edentulous subjects. The nature of the dento-alveolar apparatus and associated neuro-musculature proprioception ensures adaptation to such an increase in the vertical dimension of occlusion. ${ }^{28,29}$ If the aim is to restore the teeth to their original morphology, functional and aesthetic form then the evidence suggests that this is achievable without complication. This can be done with either a fixed ${ }^{20}$ or removable ${ }^{21}$ Dahl appliance, with a one ${ }^{8}$ or two ${ }^{24}$ stage procedure, or with $\operatorname{direct}^{8}$ or indirect $^{24}$ restorations.

Dahl and Krogstad ${ }^{24}$ used a removable appliance, the thickness of which determined the increase in the vertical dimension of occlusion. This ranged between $1.8 \mathrm{~mm}$ to $4.7 \mathrm{~mm}$ (mean=2.84mm). Gough and Setchell ${ }^{20}$ did not always have preoperative and post-operative study casts available to determine how much space was created. However they stated that the appliance allowed the teeth to be restored with indirect restorations with either minimal or no occlusal reduction. Hemmings et $a l .{ }^{8}$ and Gow and Hemmings ${ }^{10}$ placed anterior restorations at an increased vertical dimension of occlusion, which created a posterior disclusion of between $1 \mathrm{~mm}$ to $4 \mathrm{~mm}$. Redman et al. ${ }^{9}$ did not state the increase in the vertical dimension of occlusion on placement of the anterior restorations.

\section{How does it work?}

Dahl and Krogstad ${ }^{24}$ demonstrated, in the case of the anterior Dahl appliance, that the space was created by a combination of intrusion (40\%) of the anterior teeth in contact with the appliance and eruption $(60 \%)$ of the unopposed posterior teeth. More eruption than intrusion was seen in the younger age group. In some cases the time taken for tooth movement to occur is faster than that which could be achieved with orthodontic tooth movement. It has been suggested that a degree of mandibular repositioning involving the condyles might be occurring in these situations. ${ }^{8,9}$ The posterior contacts were re-established initially on the last molars and the occlusion progressively re-established more anteriorly with time. ${ }^{8,9}$

\section{How long does it take?}

The occlusion tends to re-establish after about six months on average but it can take up to a period of 18-24 months (Table 2). As mentioned before, the compliance with which a removable appliance is worn will greatly influence the speed at which the space is created. ${ }^{20,24}$

\section{What adverse events have been recorded?} The main adverse events that practitioners may be concerned with are pulpal symptoms, periodontal problems, temporomandibular joint dysfunction symptoms and apical root resorption. The available literature suggests the incidence of adverse events occurring with the Dahl concept is rare. However it must be mentioned that the quality of the evidence relating to these particular clinical aspects is weaker than other areas. This is because not all of the studies examined these areas and if they were assessed they tended to be subjective with little scientific evaluation.

\section{Pulpal symptoms}

Dahl and Krogstad, ${ }^{24}$ Hemmings et al., ${ }^{8}$ Gow and Hemmings ${ }^{10}$ and Redman et al. ${ }^{9}$ do not report the development of pulpal symptoms in their study groups. Gough and Setchell ${ }^{20}$ reported no pulpal symptoms in $94 \%$ of cases. $4 \%$ of their patients had moderate symptoms that resolved without any intervention. 2\% had pulpal symptoms that were severe enough to require root canal treatment. However this was in an extensively worn posterior tooth with a previously deep restoration. Thus, it can be seen that the incidence of pulpal symptoms is small. 
Another reason for not using a cemented Dahl appliance is that it has been reported that iatrogenic pulpal exposure has occurred during its removal. ${ }^{20}$

\section{Periodontal symptoms}

Immediately after insertion of the appliance, transient periodontal tenderness can occur. It has been reported that between $3 \%{ }^{9}$ and $10 \%{ }^{20}$ of patients have described mild periodontal symptoms of tenderness on biting immediately after insertion of the 'appliance'. These symptoms resolved as treatment progressed. No splaying of anterior teeth has been noted. ${ }^{8}$ Caution should be used when managing patients with periodontal disease or those with a reduced but healthy periodontium. It is our opinion that this type of treatment should be delayed in patients with active periodontal disease until the periodontal status is stable. It might be more sensible to use a removable occlusal splint type appliance in patients with a reduced but healthy periodontium as the appliance can be removed to facilitate optimal interproximal plaque control. The splinting effect will ensure that the force is applied in an axial direction and thereby reduce the possibility of unfavourable tooth movement. Although increased plaque accumulation has been demonstrated with a removable partial prosthesis, ${ }^{30}$ it is unlikely that this is of periodontal consequence as long as an optimum level of plaque control is maintained. ${ }^{31}$

The main problems with the Dahl concept are initial difficulties associated with chewing and speaking. Initially fine chewing can be awkward and lisping can occur. ${ }^{9,24}$ These problems are transient but the patient should be warned of them in advance.

\section{Temporomandibular joint dysfunction (TMJD) symptoms}

It has been reported that the development of any new temporomandibular joint or myofascial pain dysfunction symptoms is unlikely with this type of treatment. This may be due to case selection and that fact that TSL patients are less susceptible to TMJD symptoms anyway; however this issue does remain inconclusive. $^{32}$ If symptoms do occur, in most cases they are transient. Dahl and Krogstad stated that no patients reported any muscular fatigue. ${ }^{24}$ Hemmings et al.,$^{8}$ Gow and Hemmings, ${ }^{10}$ and Redman et $a l .{ }^{9}$ did not report the development of TMJD symptoms in their patients. Gough and Setchell ${ }^{20}$ state that $94 \%$ of patients reported no new dysfunctional symptoms, $2 \%$ had mildly increased muscular discomfort, and $4 \%$ had moderate dysfunction. However this resolved during the treatment period.

\section{Root resorption}

Orthodontic appliance therapy has been associated with the development of external apical root resorption. ${ }^{33}$ Orthodontic appliances have the potential to generate excessive forces. Whilst using a Dahl appliance, it appears that the periodontal proprioceptive feedback mechanism prevents excessive force being applied to those teeth in supra-occlusion. Within the literature, there are no reports of apical resorption associated with the Dahl concept.

\section{Dahl appliance design}

The appliance design and the material used to create the inter-occlusal space have evolved since Dahl's original cobaltchromium removable partial bite platform appliance. In Dahl's original paper two out of a total of 30 patients commencing the treatment withdrew because of the poor aesthetics associated with wearing the splint. ${ }^{24}$ In order to eliminate these problems, more aesthetically pleasing materials such as direct composite, or the provisional or definitive extra-coronal restorations $^{18}$ have been reported. Initial papers mentioned that the anterior appliances/ restorations were constructed with a flat occlusal platform in the cingulum area to occlude against the opposing dentition. ${ }^{18}$ Later restorations have been placed with no intention to create such a platform and successful space creation has occurred.

\section{A one-stage or two-stage Dahl procedure?}

The placement of restorations, or a Dahl appliance, in supra-occlusion may introduce occlusal interference. Although there is much debate within the dental profession regarding the significance of occlusal interference and the relationship with TMJ dysfunction symptoms, the literature suggests that this is not a problem with the Dahl concept. The Dahl concept is a dynamic process and it is difficult to predict the final occlusal contacts pre-operatively. During the period of occlusal reestablishment the avoidance of occlusal interference is impossible, but this appears to be of little significance. The restorative dentist should ensure that the definitive restorations work in harmony with the patient's definitive occlusal scheme. Following occlusal re-establishment the occlusal interference may have spontaneously resolved. However, if the occlusal interference still exists then adjustment of the restoration may be required to eliminate occlusal interferences, especially in excursive mandibular movements.

If a one-stage Dahl procedure has been used, adjustment of the restorations may become an issue. A one-stage Dahl procedure involves the placement of definitive indirect laboratory constructed restorations in supra-occlusion, whereby no interim appliance is used to create the inter-occlusal space. The occlusal morphology of these restorations is estimated, as it is not possible to predict the final occlusal relationship of the restorations with the opposing dentition pre-operatively. Adjustment of the restorations may be required but this may lead to weakening of the restoration, possible perforation, microleakage, sensitivity, and loss of the restoration. It is for this reason that the authors advocate a two-stage Dahl procedure using direct composite resin as the interim Dahl appliance. This is similar to Dahl and his co-workers' original principle whereby the inter-occlusal space was created using a removable cobalt-chromium appliance. Once sufficient space was created the teeth were then prepared and full coverage restorations placed.

Composite is a useful material for the creation of inter-occlusal space in twostage Dahl procedures (Figs $2 \mathrm{a}$ and $2 \mathrm{~b}$ ). The material is inexpensive, simple to use and adjust and has favourable wear characteristics. Directly bonded composite resin acts as a fixed Dahl appliance and is reversible. The composite can be easily removed for subsequent definitive extra-coronal restorations, once sufficient space creation has occurred (Figs 2c and 2d). The definitive indirect restorations can then be constructed conforming to the existing occlusal scheme and placed into a more favourable occlusal environment. The authors suggest that a two-stage Dahl technique should be adopted if the definitive restorations are going to involve some form of irreversible tooth preparation and/or the placement of laboratory constructed definitive restorations. The successful re-establishment of the occlusion with a one-stage procedure has been reported with direct, indirect and provisional restorations. ${ }^{15,19,23,34}$ However, the use of this technique, in order to reduce the

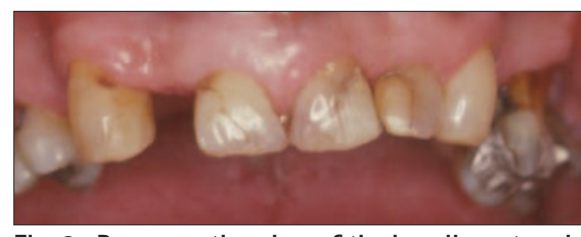

Fig. 2a Pre-operative view of the heavily restored upper anterior teeth. (Note the relatively short clinical crown heights.)

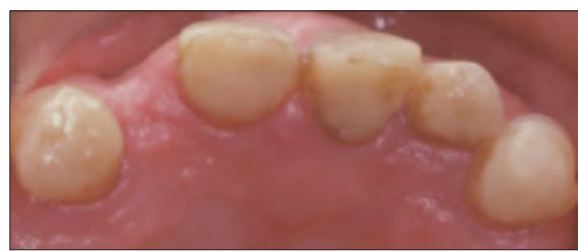

Fig. $2 \mathrm{~b}$ Direct composite restorations placed as fixed Dahl appliances. 


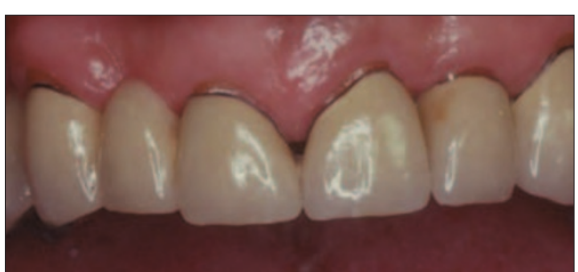

Fig. 2c Conventional metal-ceramic restorations placed once sufficient inter-occlusal space created.

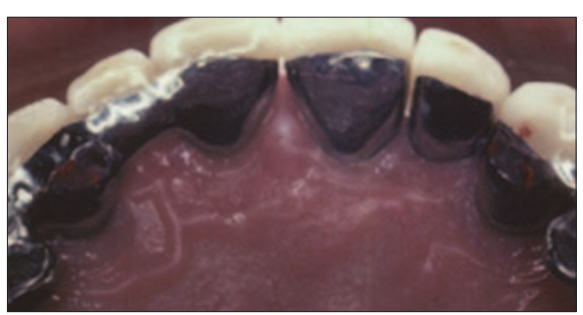

Fig. 2d Occlusal view of the conventional metalceramic restorations.

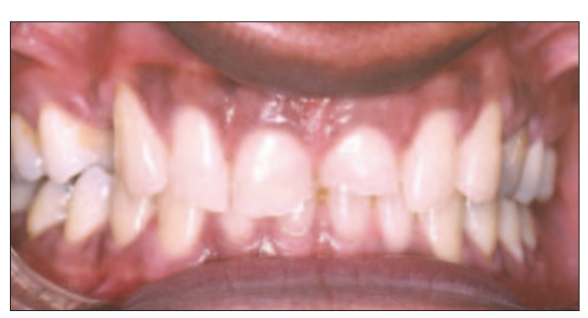

Fig. 3a Pre-operative view of the worn anterior teeth in the intercuspal position.

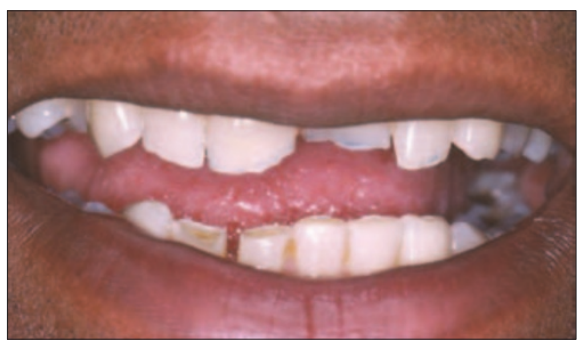

Fig. 3b Pre-operative view of the worn anterior teeth. (Note the distortion in the occlusal plane.)

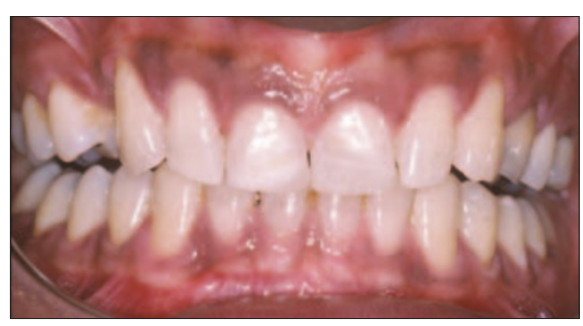

Fig. $3 c$ Immediete post-operative view (in the occlusal position of maximum intercuspation) following the placement of direct composite restorations 11, 21, 41 and 42 at an increased vertical dimension of occlusion.

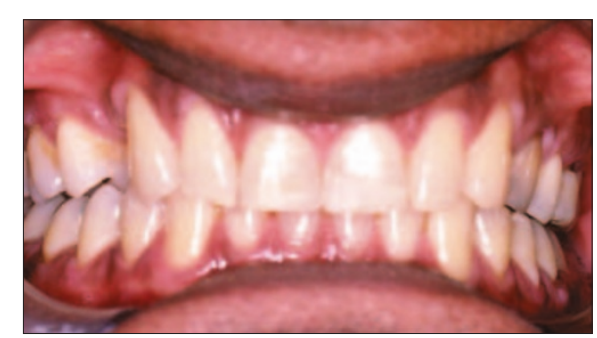

Fig. 3d Re-establishment of occlusal contacts at 3 months.

\section{Department of Restorative Dentistry \\ Maxillofacial Unit \\ St Georges' University Hospital}

\section{Managing Tooth Wear \\ Patient Information Leaflet}

\section{Why are worn down teeth a problem for people?}

People may be concerned about

- The appearance of their worn teeth

- Sensitivity associated with hot or cold drinks or foods

- Difficulty or soreness whilst chewing

- The lifespan of their teeth

Why are worn down teeth a problem for dentists?

It can be difficult to replace the lost tooth tissue in a reliable and natural looking way.

\section{How do you treat worn down teeth?}

\section{Prevention}

- Treatment is focused on preventing any further tooth loss.

- If you are aware of any of the risk factors that we have discussed you should try and limit your frequency of exposure to these.

- The use of a fluoride mouthwash daily will strengthen your teeth against wear.

- In some people who grind their teeth an appliance is made which fits over and protects the teeth.

Treatment Options

- We have discussed the options available to rebuild your teeth.

- We have decided to use an option where we bond white fillings to your worn teeth (see below).

\section{The 'Dahl' Treatment Option}

This technique has been successfully used for almost 30 years. The great advantage is that it is a less destructive treatment option as there is little or no preparation to the teeth. It is possible to build the teeth up with a white plastic filling material that is bonded to the tooth.

\section{How will it feel?}

- Initially the teeth will feel high in the bite and your back teeth will not be in contact. It usually takes patients 1-2 weeks to get used to this new bite.

- It is unusual for patients to experience pain during this treatment, however, the bite may feel a little uncomfortable initially.

- Your back teeth will come back into contact over a period of 4-6 months, however, in some patients this can take up to 1 year.

- In very few patients (2-4\%) the back teeth fail to come back into contact. If this occurs it may not concern you so no further treatment is necessary. In some patients we may have to bond fillings to the back teeth as well.

Thank you for taking the time to read this information leaflet.

If you have any further questions please do not hesitate to contact us.

Fig. 4 Patient information leaflet.

number of visits required to complete treatment, in our opinion has to be weighed up against the potential problems.

Although composite is considered as a 'temporary' material for two-stage Dahl procedures, in some clinical situations the material should now be considered as a 'medium term' definitive restoration ${ }^{9}$ (Fig. 3). The appearance and the predictability of bonding modern composites have greatly improved. It seems that a greater survival is achieved if the material is placed in sufficient bulk to avoid flexure that occurs in thin section. When managing worn mandibular incisors it is suggested that composite is the material of choice. This is especially true in TSL cases with a predominantly erosive component. The composite can be used as the fixed Dahl appliance and as the definitive restorative material, with little biological cost. However, there are a few cases in which the benefits of this conservative technique are marred due to the need for regular maintenance of the composite restorations due to chipping, debonding and/or discolouration. More research needs to be undertaken to help identify the pre-operative risk factors associated with the poor performance of composite restorations used in this way.

\section{Posterior Dahl appliance}

It has been shown in a retrospective evaluation by Chana et al. ${ }^{15}$ that alumina abraded gold metal restorations bonded with Panavia Ex are a predicable method of restoring the worn posterior dentition. In Chana et al.'s study, 12\% of the restorations were cemented in supra-occlusion as a one-stage Dahl procedure. Reassuringly it 

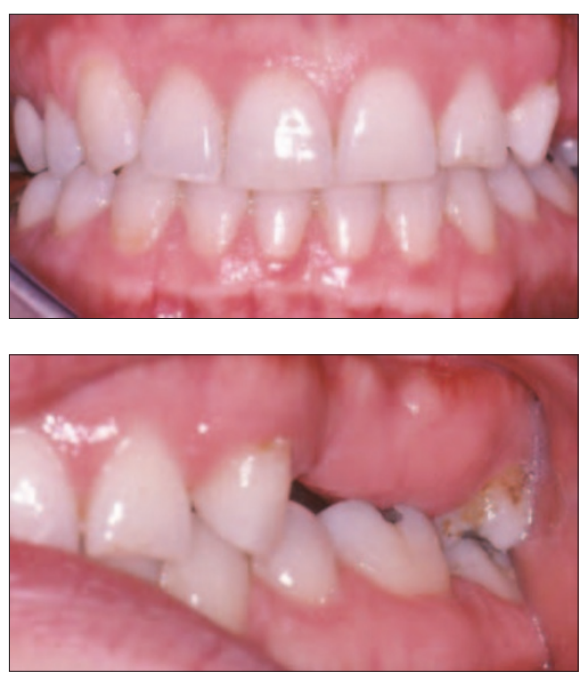

Fig. 5a Pre-operative view showing the distortion in the occlusal plane and lack of inter-occlusal space due to over-eruption of the unopposed 35 and 36.
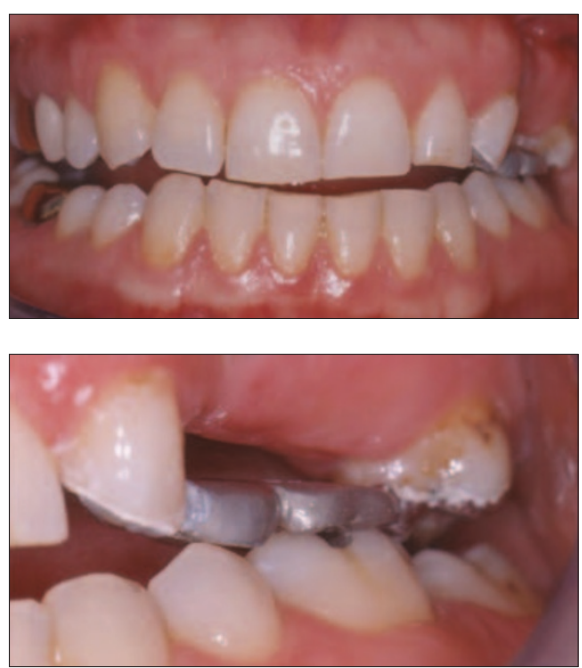

Fig. $5 b$ The cemented posterior cobalt-chromium Dahl appliance in situ. Note the significant increase in vertical dimension of occlusion.
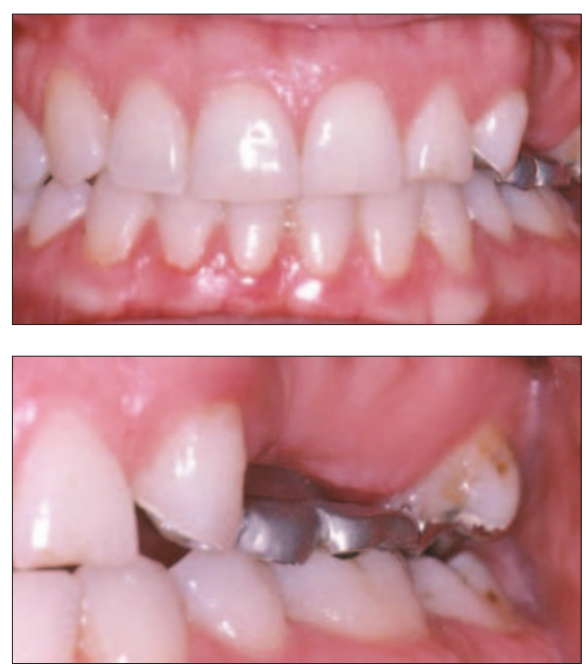

Fig. 5c Post-operative view. Full arch occlusal contacts were re-established after 3 months of wearing the appliance. was shown that these restorations placed after no preparation of inter-occlusal space were statistically no more prone to failure than those that were placed following traditional inter-occlusal tooth preparation.

\section{Patient information}

One possible reason for the apparent reluctance to use this technique might be that practitioners are unfamiliar with the evidence relating to the concept and unsure what precise information to communicate to their patients. Patients need to be fully informed prior to embarking on any form of treatment. This is equally important when using the Dahl concept, as patients will often experience a noticeable effect immediately, which to an uninformed patient might cause distress.

In our unit, where this technique is frequently used, we have a patient information leaflet relating to tooth wear and the Dahl concept (Fig. 4).

\section{FUTURE APPLICATIONS AND CHALLENGES}

The Dahl concept tends to be associated with the creation of inter-occlusal space in a) the worn dentition in a localised region and b) using multiple teeth to support the appliance which acts against multiple target teeth. Although the technique is adaptable there is a lack of scientific evidence relating to the different clinical applications. Alternative applications include the management of localised distortions of the occlusal plane, use of the technique in the restoration of the endodontically treated tooth, and the management of the worn mandibular anterior dentition.

The evidence relating to the creation of inter-occlusal space for a single tooth or correcting localised distortions of the occlusal plane is limited..$^{20,35}$ Examples of this application include cases where overeruption of a tooth or teeth has occurred following the loss of the antagonist(s) (Fig. 5), or cases where inter-occlusal space has been lost following decementation of an extra-coronal restoration. The creation of inter-occlusal space for the retainer of a resin-bonded bridge has been reported, ${ }^{19,36}$ in order to prevent the loss of precious enamel for predictable bonding.

There is no evidence relating to the application of this technique for endodontically treated teeth. Endodontically treated teeth are structurally compromised following treatment and posterior teeth usually benefit from cuspal protection. The axial preparation necessary for full coverage restorations can lead to further weakening and removal of remaining tooth tissue. The consequence of this is a reduced prognosis of the restoration and the tooth. The concept is useful for any tooth requir- ing axial tooth preparation where the creation of inter-occlusal space will challenge the viability of the tooth and require destructive methods for retention (eg post and cores). Further research is required in order to investigate the benefit of this technique compared with conventional prosthodontic approaches and to determine the influence of periapical healing on the capacity for axial tooth movement.

When managing worn mandibular incisors one may consider the placement of direct composite restorations as both fixed Dahl appliances and the definitive restorations as the treatment of choice. Given the diminutive nature of these teeth - in comparison to the rest of the dentition - any preparation for full coverage extra-coronal restorations is highly likely to have a long-term deleterious affect on the prognosis of the teeth. The authors have initiated a prospective study of the management of the worn anterior mandibular dentition with fixed intrusion composite restorations. The study will investigate the longterm clinical success, patient acceptance of this treatment modality, and attempt to determine the factors associated with failure. It will also evaluate whether minimal tooth preparation influences the performance of these restorations.

There is still an absence of comprehensive clinical and scientific research relating to the Dahl concept. Dahl et al.'s24-26 original and invaluable work is still the only study that offers some scientific reasoning behind the mechanism of relative axial tooth movement. Owing to the multiple radiographic exposures used to facilitate their work it is unlikely that ethical approval would be granted today. As more literature is published regarding the technique it appears that more questions become unanswered. What is the role of mandibular repositioning and the longterm outcome of this? Are there any orthodontic factors that can be used to predict which patients are unlikely to experience occlusal re-establishment? What is the reason for the lack of eruptive potential? In what cases should orthodontics be used rather than the Dahl concept? No further evidence is needed to support that the concept works in the majority of cases, but we need to focus on how it works and attempt to identify pre-operative factors associated with a lack of occlusal re-establishment.

\section{SUMMARY}

It is hoped that this article gives the reader an update and insight into the Dahl Concept. Although there is a need for further research, the evidence to date indicates that the technique can be confidently and successfully used in a variety of clinical situations and for many patients, irrespective of 
age or sex. The technique appears to be safe and avoids performing destructive restorative procedures on compromised teeth. The development of adverse events is very rare. If they do occur they tend to be minor in nature and transient with no long-term adverse sequelae. The Dahl concept tends to be associated with the management of the worn dentition. However, the technique could also be applied to compromised and root filled teeth, and to correct localised distortions in the occlusal plane.

1. Berry D C, Poole D F G. Attrition: Possible mechanisms of compensation. J Oral Rehabil 1976; 3: 201-206.

2 Smith B GN Knight J K. An index for measuring the wear of teeth. Br Dent J 1984; 156: 435-438.

3. Kelly M, Steele J G, Nuttall N, Bradnock G, Morris J, Nunn J et al. Adult dental health survey: Oral health in the United Kingdom 1998. London: The Stationery Office, 2000.

4. O'Brien M. Children's dental health in the United Kingdom. London: HMSO, 1994.

5. Evans R D. Orthodontics and the creation of localised inter-occlusal space in cases of anterior tooth wear. Eur J Prosthodont Rest Dent 1997; 5: 169-173.

6. Saunders W P, Saunders E M. Prevalence of periradicular periodontitis associated with crowned teeth in a adult Scottish subpopulation. Br Dent J 1998; 185: 137-140

7. Felton D, Madison S, Kanoy E, Kantor M, Maryniuk G. Long term effects of crown preparation on pulp vitality. J Dent Res 1989; 68 (special issue): 1009. Abstract 1139

8. Hemmings K W, Darbar U R, Vaughan S. Tooth wear treated with direct composite restorations at an increased vertical dimension: results at 30 months. J Prosthet Dent 2000; 83: 287-293.

9. Redman C D J, Hemming K W, Good J A. The surviva and clinical performance of resin-based composite restorations used to treat localised anterior tooth wear. Br Dent J 2003; 194: 566-572.

10. Gow A M, Hemmings K W. The treatment of localised anterior tooth wear with indirect Artglass ${ }^{\circledR}$ restorations at an increased occlusal vertical dimension. Results after two years. Eur J Prosthodont Rest Dent 2002; 10: 101-105.

11. Walls A W G. The use of adhesively retained allporcelain veneers during the management of fractured and worn anterior teeth: Part 1 Clinical technique. Br Dent J 1995: 178: 333-336.

12. Walls A W G. The use of adhesively retained allporcelain veneers during the management of fractured and worn anterior teeth: Part 2 Clinical results after 5 years of follow-up. Br Dent J 1995; 178: 337-340

13. Bishop $K$, Bell M, Briggs $P$, Kelleher M. Restoration of a worn dentition using a double-veneer technique. BrDent J 1996; 180: 26-29.

14. Bishop K A, Briggs P F, Kelleher M G D. Modern restorative management of advanced tooth-surface loss. Primary Dental Care 1994; 1(1): 20-23.

15. Chana H, Kelleher M, Briggs $P$, Hooper R. Clinical evaluation of resin-bonded gold alloy veneers. J Prosthet Dent 2000; 83: 294-300.

16. Briggs $P$, Chana H, Kelleher M, Poyser N. The clinical application of posterior resin-bonded cast metal restorations. Dental Update 2002; 29: 331-337.

17. Murray M C, Brunton P A, Osborne-Smith K Wilson N H F. Canine risers: Indications and techniques for their use. Eur J Prosthodont Rest Dent 2001; 9: 137-140.

18. Ricketts N J, Smith B G N. Minor axial tooth movement in preparation for fixed prostheses. Eur $J$ Prosthodont Rest Dent 1993: 1: 145-149.

19. Ricketts N J, Smith B G N. Clinical techniques for producing and monitoring minor axial tooth movement. Eur J Prosthodont Rest Dent 1993; 2: 5-9.

20. Gough M B, Setchell D J. A retrospective study of 50 treatments using an appliance to produce localised occlusal space by relative axial tooth movement. $\mathrm{Br}$ Dent J 1999; 187: 134-139.

21. Dahl B L, Krogstad O, Karlsen K. An alternative treatment of cases with advanced localised attrition J Oral Rehabil 1975; 2: 209-214.

22. Cousins A J, Brown W A, Harkness E M. An investigation into the effect of the maxillary bite plane on the height of the lower incisor teeth. Dent Prac and Dent Record 1969: 20.

23. Anderson D J. Tooth movement in experimental malocclusion. Arch Oral Biol 1962; 7: 7-16.

24. Dahl B L, Krogstad O. The effect of a partial bite raising splint on the occlusal face height. An $\mathrm{x}$-ray cephalometric study in human adults. Acta Odontol Scand 1982; 40: 17-24.

25. Dahl B L, Krogstad 0 . The effect of a partial biteraising splint on the inclination of upper and lower front teeth. Acta Odontol Scand 1983; 41: 311-314.

26. Dahl B L, Krogstad O. Long-term observations of an increased occlusal face height obtained by a combined orthodontic/prosthetic approach. J Oral Rehabil 1985; 12: 173-176.

27. The Royal College of Surgeons of England. Faculty of Dental Surgery. National Clinical Guidelines 1997.

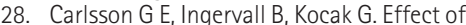
increasing vertical dimension on the masticatory system in subjects with natural teeth. J Pros Dent 1979; 41: 284-289

29. Hellsing G. Functional adaption to changes in vertical dimension. J Pros Dent 1984; 52: 867-870.

30. Addy M, Bates J F. Plaque accumulation following the wearing of different types of removable partial dentures. J Oral Rehabil 1979; 6: 111-117.

31. Bergman B, Hugoson A, Olsson C O. Caries, periodontal and prosthetic findings in patients with removable partial dentures: A ten-year longitudinal study. J Prosthet Dent 1982; 48: 506-514.

32. Selingman D A, Pullinger A G. Analysis of occlusal variables, dental attrition, and age for distinguishing healthy controls from female patients with intercapsular temporomandibular disorders. J Prosthet Dent 2000; 83: 76-82

33. Levander $E$, Malmgren 0 . Evaluation of the risk of root resorption during orthodontic treatment: a study of upper incisors. Eur J Orthodontics 1988; 10: 30-38.

34. Briggs P F, Bishop K, Djemal S. The clinical evolution of the 'Dahl Principle' Br Dent J 1997: 183: 171-176.

35. Djemal S, Bavisha K, Gilmour G. Management of a supra-erupted premolar: A case report. Dent Update 2004; 31: 220-222.

36. Briggs P, Dunne S, Bishop K. The single unit, single retainer, cantilever resin-bonded bridge. BrDentJ 1997; 181: 373-379. 